\title{
Three-Dimensional In Situ XCT Characterisation and FE Modelling of Cracking in Concrete
}

\author{
Wenyuan Ren ${ }^{D},{ }^{1,2}$ Zhenjun Yang, ${ }^{3}$ Rajneesh Sharma, ${ }^{4}$ Samuel A. McDonald, ${ }^{5}$ \\ and Paul M. Mummery ${ }^{6}$ \\ ${ }^{1}$ College of Water Resources and Architectural Engineering, Northwest A\&F University, Xianyang 712100, China \\ ${ }^{2}$ Key Laboratory of Agricultural Soil and Water Engineering in Arid and Semiarid Areas, Ministry of Education, \\ Northwest A\&F University, Xianyang 712100, China \\ ${ }^{3}$ Research Centre of Built and Natural Environment, Coventry University, Coventry CV1 5FB, UK \\ ${ }^{4}$ School of Engineering, Indian Institute of Technology Mandi, Mandi, India \\ ${ }^{5}$ Manchester X-ray Imaging Facility, School of Materials, The University of Manchester, Manchester M13 9PL, UK \\ ${ }^{6}$ School of Mechanical, Aerospace and Civil Engineering, The University of Manchester, Manchester M13 9PL, UK \\ Correspondence should be addressed to Wenyuan Ren; wenyuange304@nwsuaf.edu.cn
}

Received 25 March 2018; Revised 8 June 2018; Accepted 19 June 2018; Published 18 July 2018

Academic Editor: Shoujun Huang

Copyright (c) 2018 Wenyuan Ren et al. This is an open access article distributed under the Creative Commons Attribution License, which permits unrestricted use, distribution, and reproduction in any medium, provided the original work is properly cited.

\begin{abstract}
Three-dimensional (3D) characterisation and modelling of cracking in concrete have been always of great importance and interest in civil engineering. In this study, an in situ microscale X-ray computed tomography (XCT) test was carried out to characterise the 3D microscale structure and cracking behaviour under progressive uniaxial compressive loading. The 3D cracking and fracture behaviour including internal crack opening, closing, and bridging were observed through both $2 \mathrm{D}$ tomography slices and 3D CT images. Spatial distributions of voids and cracks were obtained to understand the overall cracking process within the specimen. Furthermore, the XCT images of the original configuration of the specimen were processed and used to build microscale realistic 3D finite element (FE) models. Cohesive interface elements were inserted into the FE mesh to capture complicated discrete crack initiation and propagation. An FE simulation of uniaxial compression was conducted and validated by the in situ $\mathrm{XCT}$ compression test results, followed by a tension simulation using the same image-based model to investigate the cracking behaviour. The quantitative agreement between the FE simulation and experiment demonstrates that it is a very promising and effective technique to investigate the internal damage and fracture behaviour in multiphasic composites by combining the in situ micro XCT experiment and image-based FE modelling.
\end{abstract}

\section{Introduction}

Multiscale experiments and modelling of quasi-brittle multiphase materials, such as concrete, bones, and various composite materials, have received increasing interests in order to gain a better understanding of their failure mechanisms [1]. Among a variety of influence factors, the material microstructure and the characterisation of complex damage evolution in the microscale are fundamentally important. An improved understanding of 3D cracking in concrete can be achieved by multiscale experiments and numerical modelling based on realistic microstructures, for the development of materials with higher strength, durability, and fracture resistance.

Conventional mechanical tests have been extensively used in previous studies, but these tests can only obtain overall material properties and limited information about cracking inside the specimens. Recent advances in imaging techniques, especially the $3 \mathrm{D}$ micro X-ray computed tomography (XCT) technique, have made it possible to characterise microstructures for various composite materials with high resolution but without destruction of the materials. For example, it has been applied to characterisation of steel fibres in self-compacting concrete [2], measurement of 


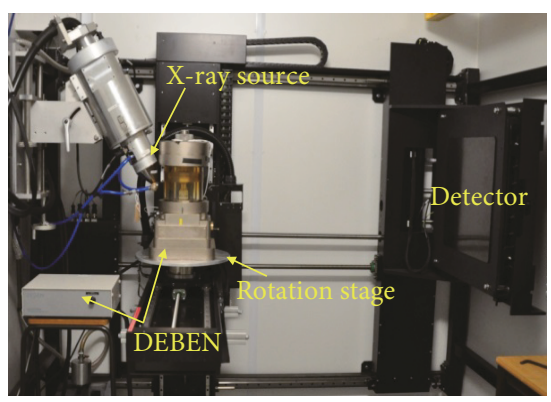

(a) XCT instrument

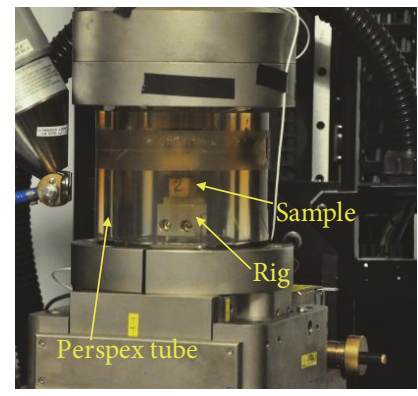

(b) DEBEN system

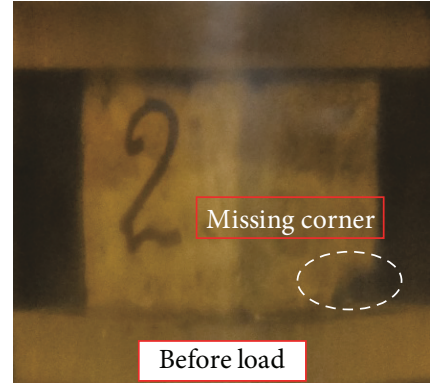

(c) Sample

Figure 1: The in situ XCT facility with DEBEN loading system and the sample before loading.

TABLE 1: XCT imaging parameters.

\begin{tabular}{lccccc}
\hline Exposure time $(\mathrm{s})$ & Voltage $(\mathrm{kV})$ & Beam current $(\mu \mathrm{A})$ & Projections & Rotation degree $\left(^{\circ}\right)$ & Voxel size $(\mu \mathrm{m})$ \\
\hline 1.4 & 100 & 200 & 1500 & 360 & 16.5 \\
\hline
\end{tabular}

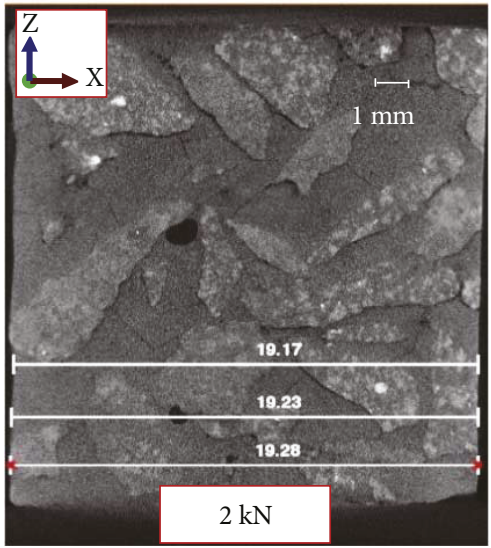

(a)

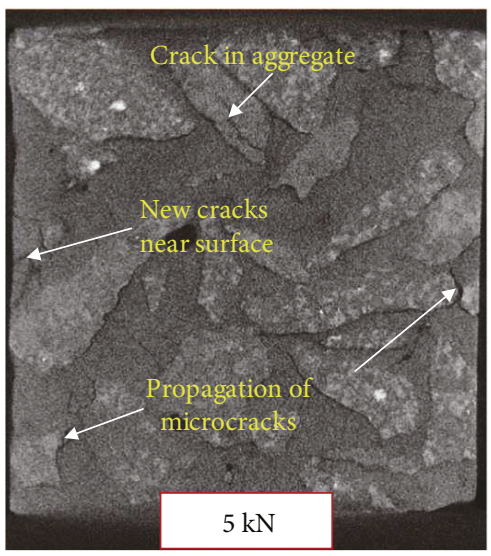

(c)

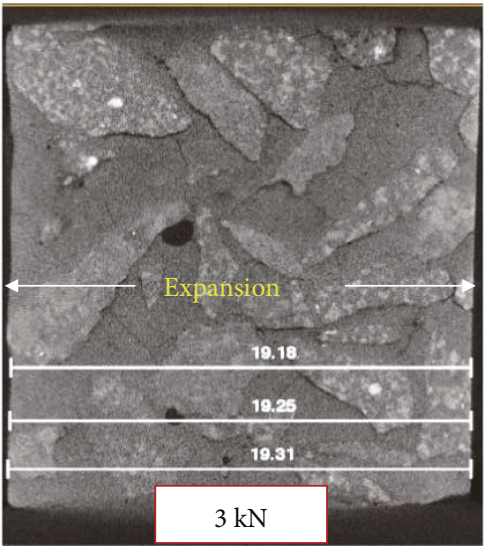

(b)

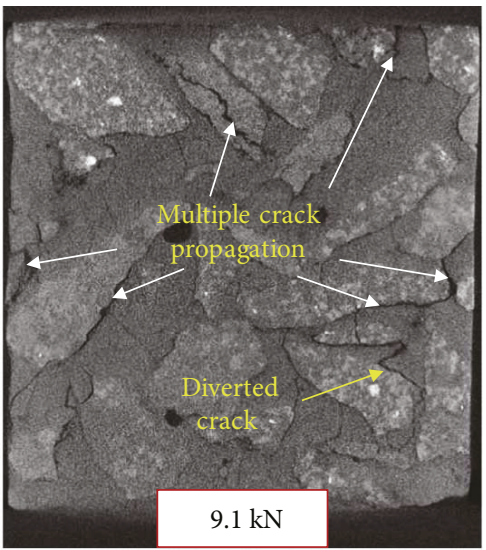

(d)

FIGURe 2: Propagation of internal microcracks in a CT slice as the load increases.

porosity and aggregate properties in porous concrete [3], shape and surface analyses of coarse aggregates in normal and lightweight concrete $[4,5]$, and evaluation of microarchitectures of limestone and trabecular bones [6]. In situ
XCT tests, which scan 3D internal microstructures under progressive loading and environmental factors so that the structural damage and fracture evolution can be examined in relation to external factors, have also been rapidly 


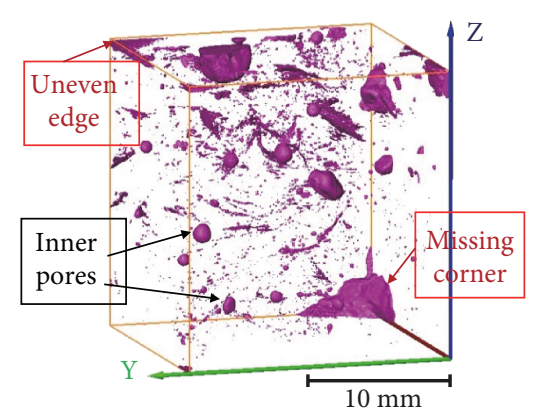

(a) $0 \mathrm{kN}$

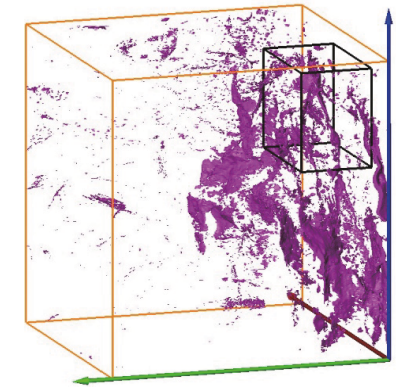

(b) $9.1 \mathrm{kN}$

FIgURE 3: Segmented cracks and voids under (a) $0 \mathrm{kN}$ and initiated cracks at (b) $9.1 \mathrm{kN}$.

developed and increasingly applied in different engineering fields [7-10].

Computational simulations of concrete fracture have been an active research field since the 1960s [11]. Recently, microscale realistic image-based finite element (FE) models $[1,12,13]$ have been proposed and received extensive attention. In comparison with numerical models using idealised microscale morphologies [14-16] or assumed stochastically random field properties [17], the image-based models faithfully reproduce the intrinsic heterogeneity of the material, such as shape, size, and distribution of inclusions and pores [18]. Moreover, the simulated results at different loading steps can be quantitatively validated by in situ experimental images (e.g., XCT) $[9,19]$.

Cohesive crack model first developed by Hillerborg et al. [20] is becoming attractive, due to its ability of modelling macroscopic cracks with strong discontinuities, capability of realistically representing the fracture process, and the ease of implementation in general-purpose FE packages $[1,15]$. Crack propagation is modelled by automatic opening, bridging, merging, and closing of the cohesive elements $[17,21]$.

As an extension to the authors' previous in situ XCT tests [19], this follow-up study used the simpler uniaxial compression loading condition rather than the Brazilianlike concentrated splitting, and the size of the concrete cube was halved to obtain imaging results of $3 \mathrm{D}$ microscale structure and cracking process with higher voxel resolution. Nonlinear FE simulations based on the realistic microstructure were then performed and validated by the in situ test results. Finally, the XCT image-based FE models were simulated under uniaxial tension to investigate complicated fracture process.

\section{In Situ XCT Experiment}

A $20 \mathrm{~mm}$ concrete cube was prepared with ordinary Portland cement and gravel aggregates of $5 \mathrm{~mm}$ average diameter. The mass mix ratio of cement, water, and aggregates was $1.0: 0.6: 4.0$. The XCT machine used was the $225 / 320 \mathrm{kV}$ Nikon XTEK custom bay, located at the Manchester X-ray Imaging Facility. The progressive loading was applied by a DEBEN mechanical testing rig $[22,23]$ with a load capacity of $25 \mathrm{kN}$, placed on the rotation stage of the CT machine.

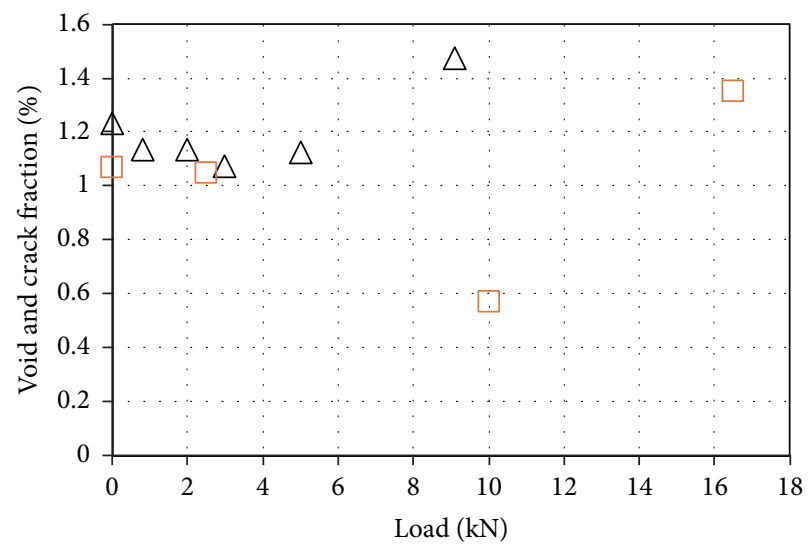

$\triangle 20 \mathrm{~mm}$

$40 \mathrm{~mm}$

FIgURE 4: Evolution of volume fraction of voids and cracks.

Figure 1(c) shows the specimen before loading with a corner defect produced during preparation. The Perspex tube of the DEBEN rig allows the transmission of the reaction force without blocking the X-ray at all rotation angles. The tungsten target and Perkin Elmer $2048 \times 2048$ pixel amorphous silicon flat panel detector were used. The detailed imaging parameters are shown in Table 1.

The initial scan was taken without any load $(0 \mathrm{kN})$. The compressive load was then applied to $0.8 \mathrm{kN}$ at a displacement rate of $0.05 \mathrm{~mm} / \mathrm{min}$, at which point the second scan was carried out. The force was then further increased to $2 \mathrm{kN}$ at the same rate with the third scan. The fourth, fifth, and sixth scans were conducted at $3 \mathrm{kN}, 5 \mathrm{kN}$, and $9.1 \mathrm{kN}$, respectively. Each scan took about half an hour.

Firstly, the projection images collected by the detector were reconstructed using filtered back-projection technique. For each scan, a total of 1500 projections with $16.5 \mu \mathrm{m}$ pixel size were obtained. The artificial defects such as beam hardening and ring effects reduce the quality of scanned images and hence affect later segmentation results. They were minimised and further corrected by postprocessing using CT Pro (e.g., finding the true centre of rotation) and AVIZO [24] (e.g., using background and flat-field correction filters). 


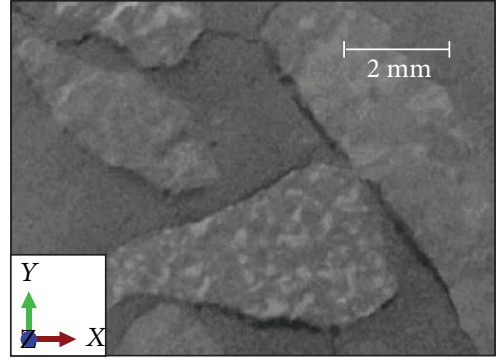

(a) $3 \mathrm{kN}$

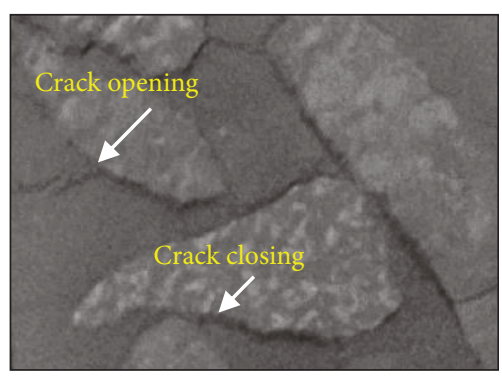

(b) $5 \mathrm{kN}$

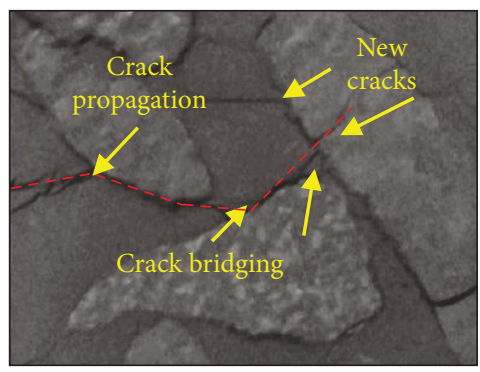

(c) $9.1 \mathrm{kN}$

FIGURE 5: Localised cracking in a subvolume (XY slice).

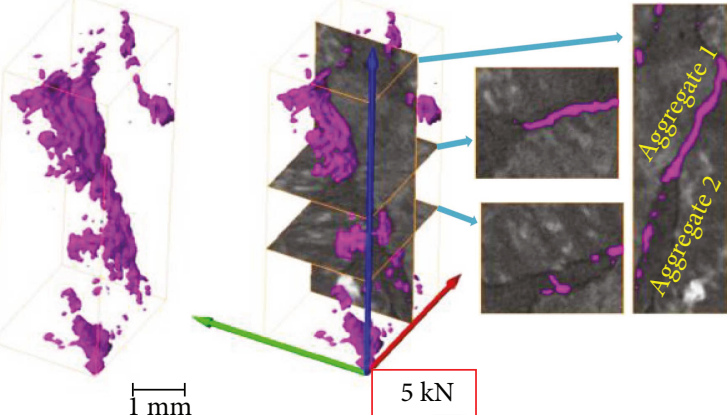

(a)

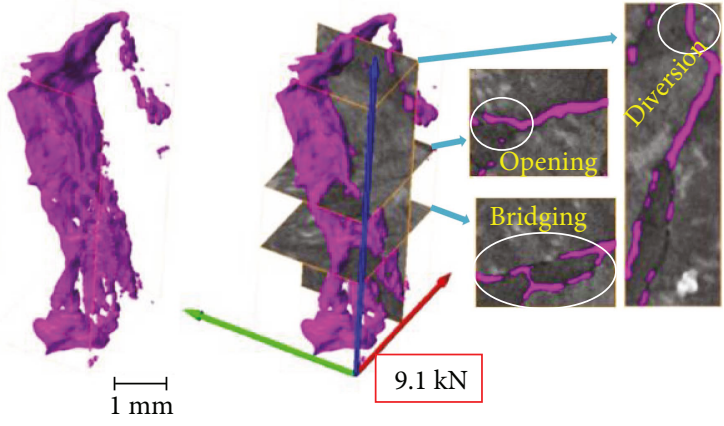

(b)

Figure 6: 3D crack surface and slice views under $5 \mathrm{kN}$ and $9.1 \mathrm{kN}$.

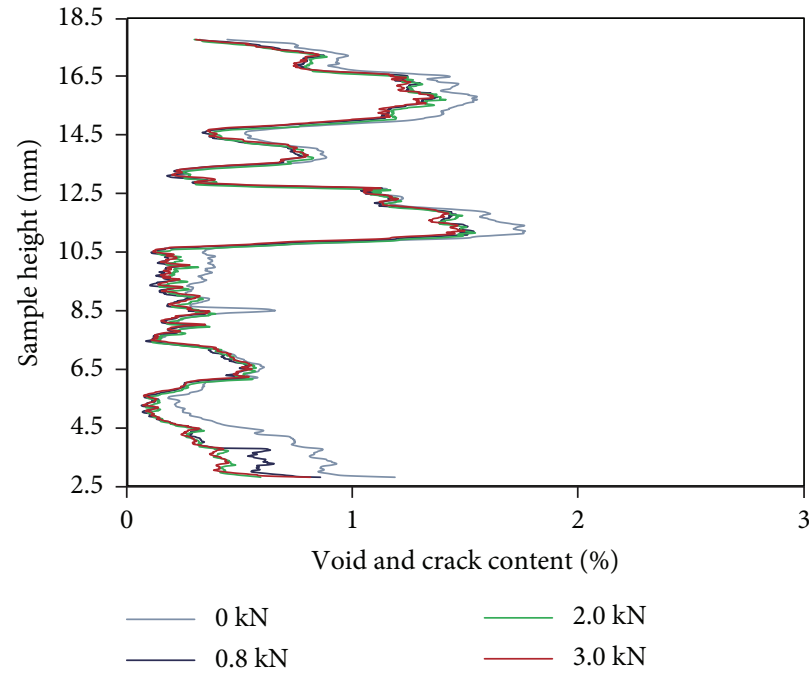

(a) Under $0 / 0.8 / 2 / 3 \mathrm{kN}$

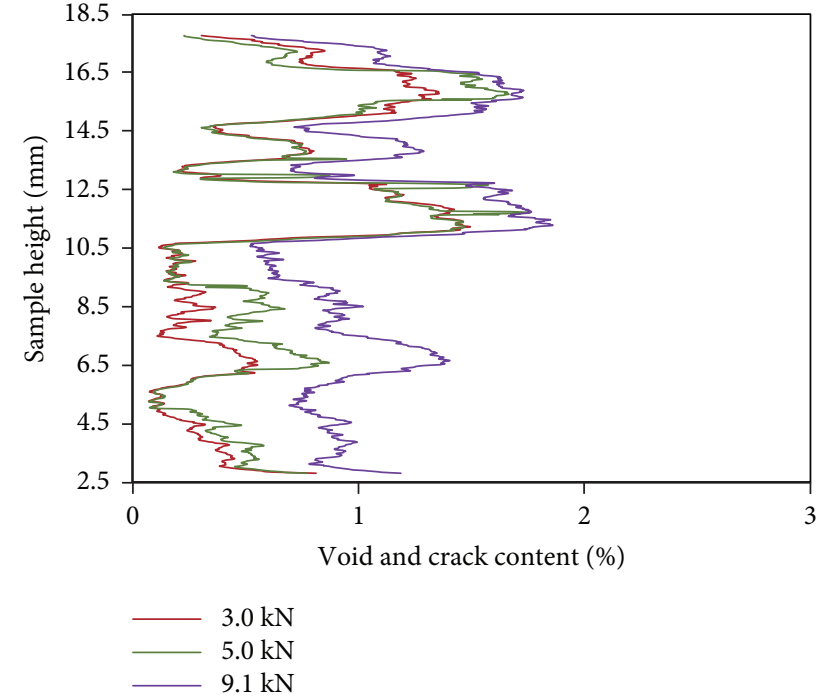

(b) Under $3 / 5 / 9.1 \mathrm{kN}$

FIGURE 7: The content of voids and cracks along the specimen height direction throughout loading steps.

\section{Experimental Results and Discussion}

3.1. $2 D$ Observations of Damage in the Specimen. After unloading, several surface cracks were evident. One corner of the specimen spalled off when the specimen was unloaded. Figure 2 shows the images (in the $X Z$ plane) for one vertical slice at four loads applied in the $Z$ direction. Little difference was found between the two images at $2 \mathrm{kN}$ and $3 \mathrm{kN}$. However, after measuring the width of the sample, it becomes clear that gradual horizontal expansion (in the $X$ direction) occurred in the specimen. At $5 \mathrm{kN}$, multiple microcracks appeared inside the mortar, some initial microcracks 


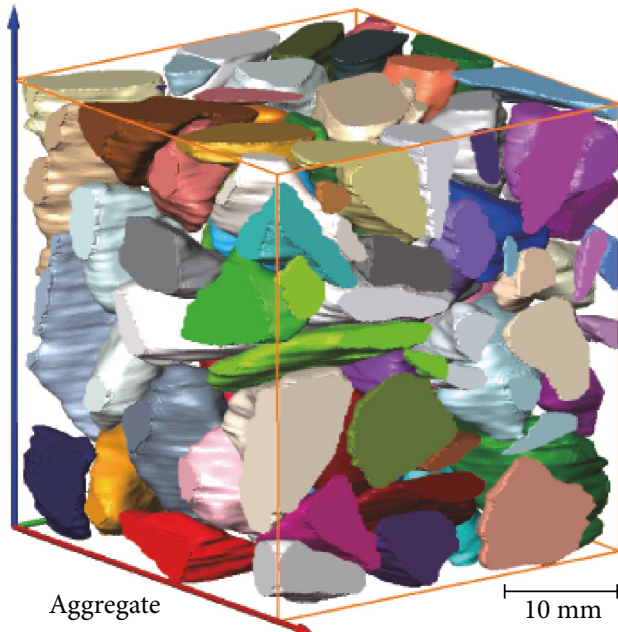

(a)

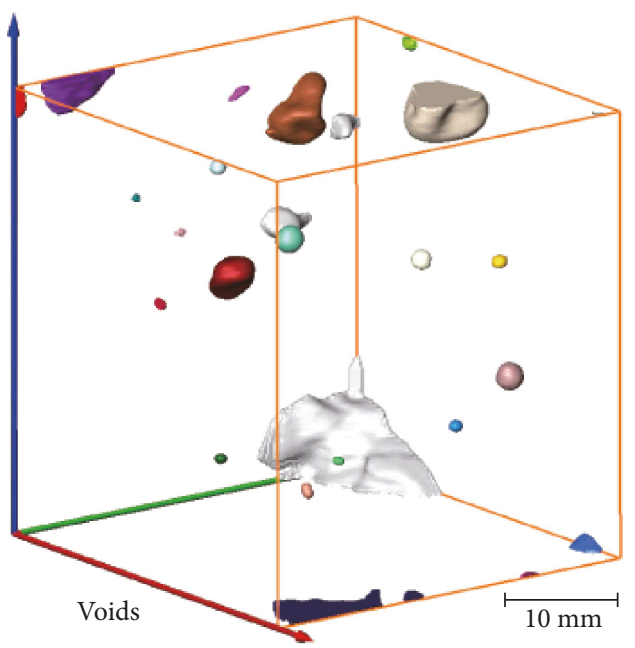

(c)

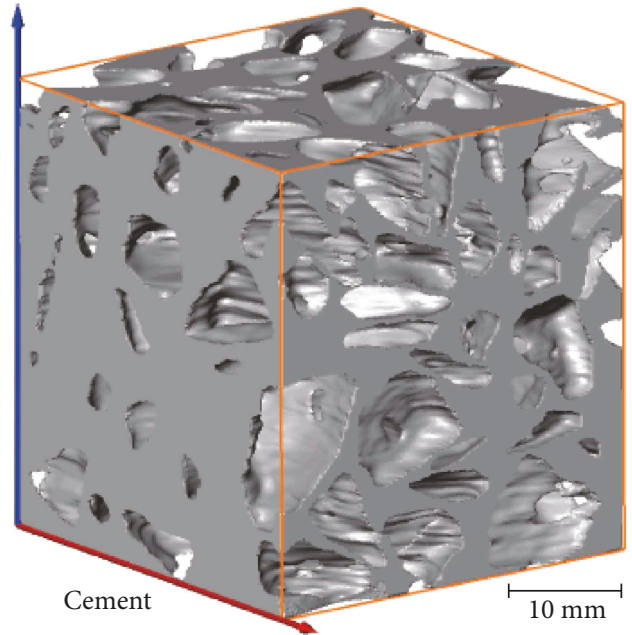

(b)

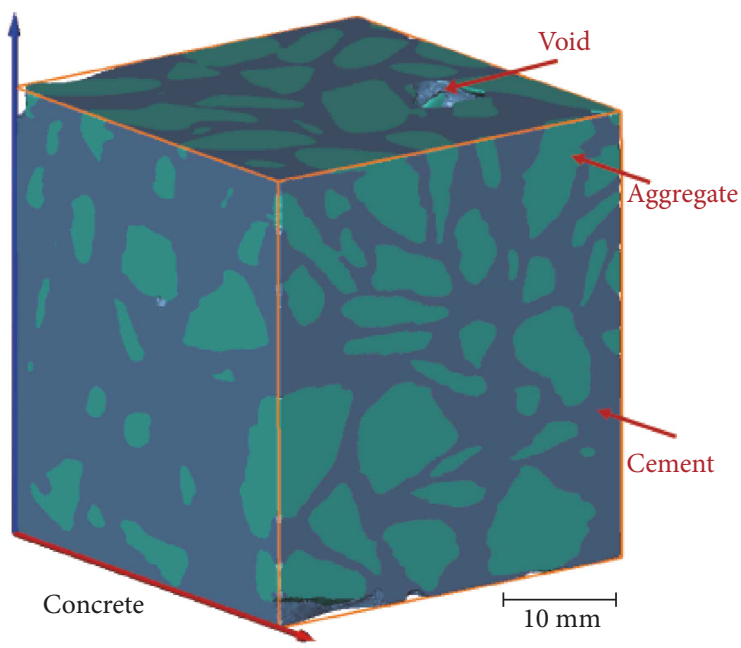

(d)

Figure 8: 3D segmentation of the specimen before loading.

propagated, and a microcrack even appeared in an aggregate. When the load reached $9.1 \mathrm{kN}$, many cracks propagated further and crack diversion could be seen around aggregates.

\section{2. $3 D$ Crack Characterisation. As the voxels in $\mathrm{CT}$ images} for voids and cracks were greatly different from those for aggregates and cement, the simple threshold-based segmentation method was used to identify each constituent phase. Figure 3(a) shows the defects in the specimen before loading, including uneven edges, inner pores, and the missing corner. Figure 3(b) shows the propagated cracks and initiated cracks at $9.1 \mathrm{kN}$. As there were a very limited number of microcracks at $3 \mathrm{kN}$ and $5 \mathrm{kN}$, the corresponding propagated cracks were excluded. At the max loading $9.1 \mathrm{kN}$, a large amount of new vertical (in the $Z$ direction) cracks appeared, concentrated near the highly damaged corner.

Figure 4 shows the evolution of volume fraction of voids and cracks (the voids corresponding to the missing corner and the uneven edges are excluded). The total volume of voids and cracks decreased from $0 \mathrm{kN}$ to $3 \mathrm{kN}$. This was attributed to the compaction of concrete. As the load
TABLE 2: Volume fractions of each phase in segmented $40 \mathrm{~mm}$ and $20 \mathrm{~mm}$ cubes.

\begin{tabular}{lcc}
\hline Experiment & $40 \mathrm{~mm}$ cube test $(\%)$ & $20 \mathrm{~mm}$ cube test $(\%)$ \\
\hline Aggregate & 49.6 & 54.8 \\
Cement & 49.3 & 44.1 \\
Defects & 1.1 & 1.1 \\
\hline
\end{tabular}

increased from $3 \mathrm{kN}$ to $5 \mathrm{kN}$, new cracks initiated and the existing cracks gradually propagated, reflected by the increase of the total volume of voids and cracks. At the peak load $9.1 \mathrm{kN}$, the major vertical cracks propagated (see Figure 3(b)), leading to significant dilation of the whole specimen. A similar trend was obtained for a $40 \mathrm{~mm}$ specimen, as reported in [19].

3.3. Subvolume Microcracking. A small subvolume (the block illustrated in Figure 3(b)) was cropped from the damaged top corner of the specimen for more detailed examination. Figure 5 illustrates the localised cracking behaviour within 


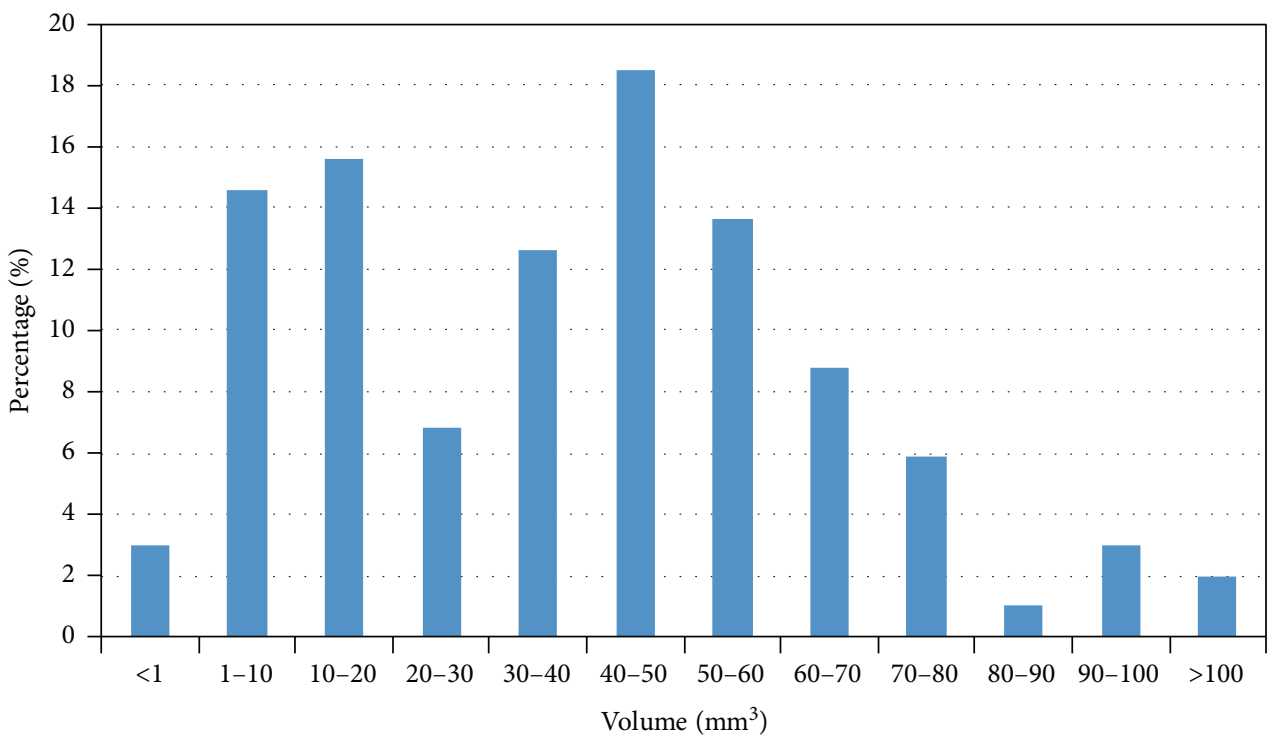

FIGURE 9: Volume distribution of aggregates.

TABLE 3: Statistical analysis for aggregates in the cube.

\begin{tabular}{lcccc}
\hline & Volume $\left(\mathrm{mm}^{3}\right)$ & Equivalent diameter $(\mathrm{mm})$ & Length $(\mathrm{mm})$ & Width $(\mathrm{mm})$ \\
\hline Min & 0.02 & 0.31 & 0.83 & 0.20 \\
Max & 112.11 & 5.98 & 12.25 & 5.91 \\
Mean & 39.09 & 3.88 & 7.37 & 2.74 \\
Standard deviation & 26.32 & 1.24 & 2.22 & 1.11 \\
\hline
\end{tabular}

this volume. Very small differences were found before $3 \mathrm{kN}$. At $5 \mathrm{kN}$, crack opening and closing occurred, mainly in the cement paste and on the aggregate-cement interfaces. When the load was increased to $9.1 \mathrm{kN}$, crack bridging occurred mostly near interfacial cracks. Some cracks were then connected, causing the major damage (see the red dashed line in Figure 5(c)).

Furthermore, the segmented 3D cracks in the subvolume under $5 \mathrm{kN}$ and $9.1 \mathrm{kN}$ loads are illustrated in Figure 6. The cracking features such as crack opening and bridging in $2 \mathrm{D}$ slices shown in Figure 5 can be seen more clearly in 3D. It is also interesting to note that the cracks always initiated along interfaces between aggregate and cement or between aggregate particles (aggregates 1 and 2 in Figure 6). Finally, either crack bridging or diversion happened when they further propagated.

3.4. Evolution of Void and Crack Content. Based on the segmented spatial distribution of voids and cracks, the calculated contents of voids and cracks at different loads were shown in Figure 7, which were derived from multiple segmented horizontal slices made through specimen height ( $Z$ direction). For each distribution, only the central part with a height of $15 \mathrm{~mm}$ (from $Z=2.8 \mathrm{~mm}$ to $Z=17.8 \mathrm{~mm}$ ) was plotted to avoid the uncertainty associated with uneven edges and the missing corner. The volume fraction of voids and cracks for each slice was calculated and then plotted along the height of the specimen. The plots clearly showed the

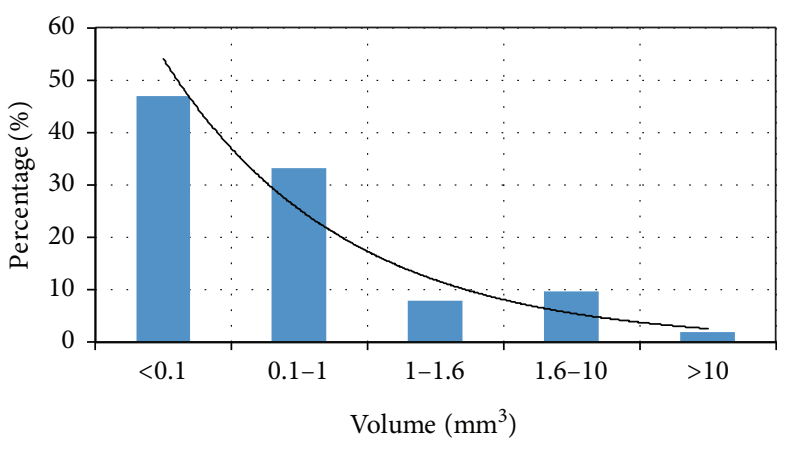

FIGURE 10: Volume distribution of voids.

inherent heterogeneity in terms of voids and cracks both before and during the compression. This heterogeneity strongly influenced the overall mechanical responses of concrete. From Figure 7, it is seen that the content of voids and cracks in the middle of the specimen was less than $2 \%$ and had several peaks. These peaks may represent one or more large inner pores, which were related to the segmented $3 \mathrm{D}$ voids (see middle part of Figure 3(a)). According to Yuan and Harrison [25] and Erdem et al. [26], such initial defects and heterogeneous microstructure would significantly intensify the transverse tensile strains during compression and stress concentration around the pores. Accordingly, they 
TABLE 4: Statistical analysis for voids in the concrete cube.

\begin{tabular}{lcccc}
\hline & Volume $\left(\mathrm{mm}^{3}\right)$ & Equivalent diameter $(\mathrm{mm})$ & Length $(\mathrm{mm})$ & Width $(\mathrm{mm})$ \\
\hline Min & 0.001 & 0.12 & 0.11 & 8.47 \\
Max & 18.65 & 3.29 & 1.67 & 0.11 \\
Mean & 0.96 & 0.72 & 1.80 & 0.63 \\
Standard deviation & 2.84 & 0.62 & 0.57 \\
\hline
\end{tabular}

represent weak regions for failure, accelerate crack propagation, and lead to final failure of the concrete specimen [19].

Recalling the evolution of the content of voids and cracks during the compression (see Figure 4), it is shown that the total volume of voids and cracks is firstly reduced with the load increasing from $0 \mathrm{kN}$ to $0.8 \mathrm{kN}$ (see Figure $7(\mathrm{a})$ ). The content stayed similar when the load was $0.8 \mathrm{kN}, 2 \mathrm{kN}$, and $3 \mathrm{kN}$. Then, the cracks were increased significantly, especially in the regions near large pores, see the differences of the curves between $3 \mathrm{kN}$ and $5 \mathrm{kN}$ as shown in Figure $7(\mathrm{~b})$. And finally, the volume of voids and cracks reached its maximum value at $9.1 \mathrm{kN}$.

3.5. Mesoscale Structure Characterisation. For the convenience of image processing, the concrete cube was cropped into a $19.5 \mathrm{~mm} \times 19.1 \mathrm{~mm} \times 20.7 \mathrm{~mm}$ volume. Meanwhile, the voxel resolution of the XCT image was resampled from $16.5 \mu \mathrm{m}$ to $100 \mu \mathrm{m}$. The segmented aggregates, cement, voids, and the whole model at $0 \mathrm{kN}$ are shown in Figure 8. The 108 aggregates are displayed in different colours for clarity.

The volume fractions of all the constituent phases in the segmented cube are listed in Table 2, compared with the previous test data of a $40 \mathrm{~mm}$ cube. For the current $20 \mathrm{~mm}$ cube, the aggregate phase occupies the most space at $54.8 \%$ in volume, followed by the cement paste at $44.1 \%$, and defects (excluding the missing corner) at $1.1 \%$. Compared to the $40 \mathrm{~mm}$-cube experiment, $4.8 \%$ and $5.9 \%$ variations were found for the aggregate and cement, respectively, which can be mainly attributed to two factors. Firstly, the present cube specimen was merely $1 / 8$ of the original specimen, which may cause a different phase volume fraction. Secondly, the volume fraction of each phase can be somewhat dependent on the image processing and segmentation due to the variance of scanning parameters (e.g., around $\pm 3 \%$ difference before and after segmentation was found for aggregates of $20 \mathrm{~mm}$ cube).

Figure 9 shows the volume distribution of aggregates with statistical data summaries in Table 3 . The majority of aggregate volumes (i.e., $81 \%, 84$ out of 103) has the size between 1 and $60 \mathrm{~mm}^{3}$ with a mean value of $39 \mathrm{~mm}^{3}$. The mean length and width are $7.37 \mathrm{~mm}$ and $2.74 \mathrm{~mm}$, respectively. The mean equivalent diameter of all the aggregates is $3.88 \mathrm{~mm}$ with a standard deviation of $1.24 \mathrm{~mm}$, which is close to $5 \mathrm{~mm}$ diameter in the mix design. These data could be used for aggregate shape analysis [27-29].

There are 51 voids in total (excluding the missing corner). The volume distribution is shown in Figure 10, and the statistical data are listed in Table 4 . The mean volume is $0.96 \mathrm{~mm}^{3}$, only $1 / 40$ of the aggregates, and the mean

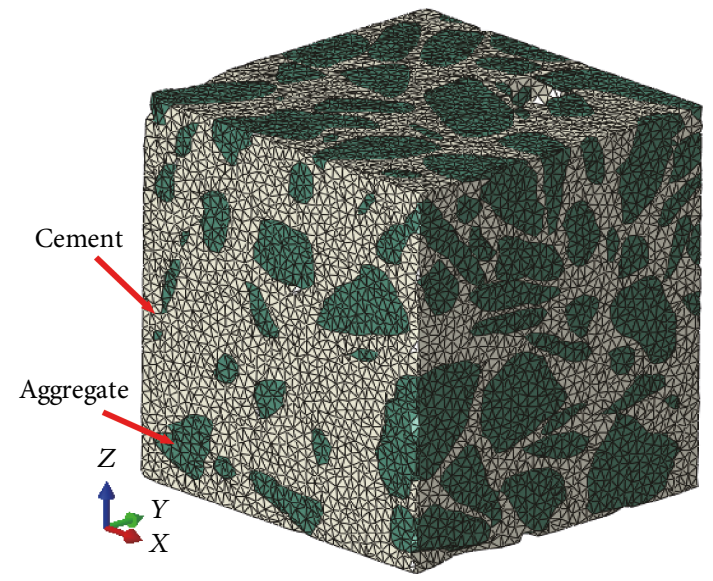

FIgUre 11: The XCT image-based FE mesh.

equivalent diameter is $0.72 \mathrm{~mm}$. The calculated aggregate and void distribution datasets can be used for generating random concrete structures $[15,30]$.

\section{XCT Image-Based FE Simulations}

4.1. 3D Model Generation. The segmented 3D image, as shown in Figure 8, was used to generate the 3D FE mesh by commercial packages AVIZO [24] and Simpleware [31]. Figure 11 shows the generated mesh with 981,919 tetrahedrons using target minimum and maximum edge lengths of $0.1 \mathrm{~mm}$ and $0.5 \mathrm{~mm}$.

The cohesive interface element (CIE) COH3D6 in ABAQUS [32] with softening laws was inserted between all common faces of adjacent elements to model potential cracks using the algorithm developed in $[1,33,34]$. The solid elements for aggregates and cement were assumed linear elastic. Three sets of CIEs were defined, namely, CIE_AGG within the aggregate, CIE_CEM within the cement paste, and CIE_INT on the aggregate-cement interfaces. The linear tension/shear softening laws were used, together with the quadratic nominal stress initiation criterion, the energybased damage evolution, and the mixed-mode BK-law fracture energy criterion [32]. The material properties are shown in Table 5. Young's moduli of the aggregates and the cement were $51 \mathrm{GPa}$ and $13.6 \mathrm{GPa}$, respectively, obtained by microindentation tests [19]. The elastic stiffness in the shear directions was assumed to be the same as that in the normal direction. The cohesive shear strength was assumed to be twice the cohesive normal strength. A power of two was used to define the BK-law fracture energy criterion, and the shear fracture energy was assumed to be 10 times the normal 
TABLe 5: Material properties.

\begin{tabular}{lcccccc}
\hline & $\begin{array}{c}\text { Young's modulus } \\
(\mathrm{MPa})\end{array}$ & Poisson's ratio & $\begin{array}{c}\text { Density } \\
\left(\mathrm{kg} / \mathrm{m}^{3}\right)\end{array}$ & $\begin{array}{c}\text { Elastic stiffness } \\
(\mathrm{MPa} / \mathrm{mm})\end{array}$ & $\begin{array}{c}\text { Cohesive strength } \\
(\mathrm{MPa})\end{array}$ & $\begin{array}{c}\text { Fracture energy } \\
(\mathrm{N} / \mathrm{mm})\end{array}$ \\
\hline Aggregate & 51,000 & 0.2 & 2500 & $/$ & $/$ & $/$ \\
Cement & 13,600 & 0.2 & 2200 & $/$ & $/$ & $/$ \\
CIE_AGG & $/$ & $/$ & 2500 & $10^{6}$ & 1 \\
CIE_CEM & $/$ & $/$ & 2200 & $10^{6}$ & 6 & 3 \\
CIE_INT & $/$ & $/$ & 2200 & $10^{6}$ & 0.06 & 0.03 \\
\hline
\end{tabular}

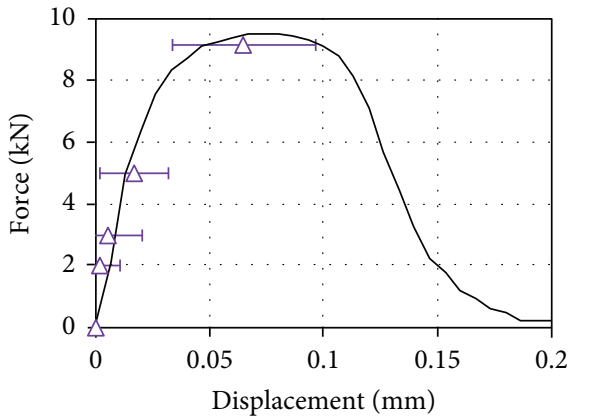

$\triangle$ Exp-DVC

- FE simulation

(a) Force-displacement curve

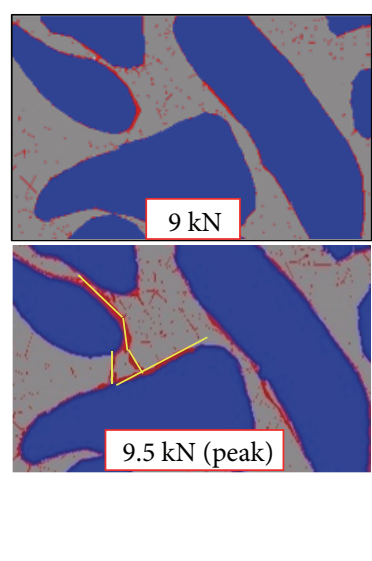

(b) Crack evolution $\left(\mathrm{DSF}=100^{*}\right)$

FIGURE 12: Force-displacement curve and crack evolution validation. * DSF is displacement scale factor.

fracture energy [21]. The bottom surface nodes were fixed, and the uniaxial compressive force was applied to the top surface nodes by using displacement-controlled loading scheme. The explicit solver with multiple cores was used to speed up the computation. The total loading time of $0.01 \mathrm{~s}$ was used after trial and error to ensure a quasi-static simulation.

4.2. Validation of Uniaxial Compression Simulation. Due to the compliance of the loading rig and the limitations of XCT setup, the recorded displacements were not accurate [19]. The calculated vertical stiffness from the experimental force-displacement curve is only about $2 \mathrm{GPa}$, much lower than normal-strength concrete (20-30 GPa). More accurate displacements can be calculated by a direct comparison of CT images before and after the deformation occurs, namely, the digital volume correlation (DVC) technique. The DVC has recently emerged as an effective approach to calculate full 3D internal displacement and strain fields, particularly in combination with high-resolution XCT images $[19,35,36]$. The LaVision Davis software was used [37] to perform the DVC in this study, using a window size of $128 \times 128 \times 128$ voxels, a $50 \%$ overlap, and a 2 -passes correlation. To reduce potential influences caused by rigid body motion during the test, registration operations (e.g., aligning centre and principal axes) were carried out. The experimental force- displacement relationship with error bar calculated from the DVC is shown in Figure 12(a) (Exp-DVC). The linear fit for the first three loading steps $(0-3 \mathrm{kN})$ gives a reasonable estimation of elastic modulus of concrete, that is, 23.6 GPa measured by microindentation [19]. The forcedisplacement curve obtained from FE simulation is also shown in Figure 12(a). The initial stiffness calculated at $3 \mathrm{kN}$ and the peak load are $23.6 \mathrm{GPa}$ and $9.5 \mathrm{kN}$, respectively. They are very close to $20.6 \mathrm{GPa}$ and $9.1 \mathrm{kN}$ in the XCT test, respectively. The crack evolution in the subvolume from FE simulation is shown in Figure 12(b). A broad similarity from the experiment (Figure 5) and FE simulation is obtained. Crack bridging by connecting interfacial cracks is found similar like the characterised phenomenon from XCT test.

4.3. Simulation of Uniaxial Tension. The same XCT imagebased FE model in Figure 11 was simulated under uniaxial tension. Same boundary conditions and loading scheme were used only with a uniaxial tension loading direction. The results are compared with the results reported in [21] using the same material parameters listed in Table 5. Figure 13 shows the stress-strain curves and the simulated cracking process at different loading stages. It can be seen that almost identical initial elastic stress-strain response and similar overall behaviour were predicted in comparison with the experiment. The differences of peak loads and softening 


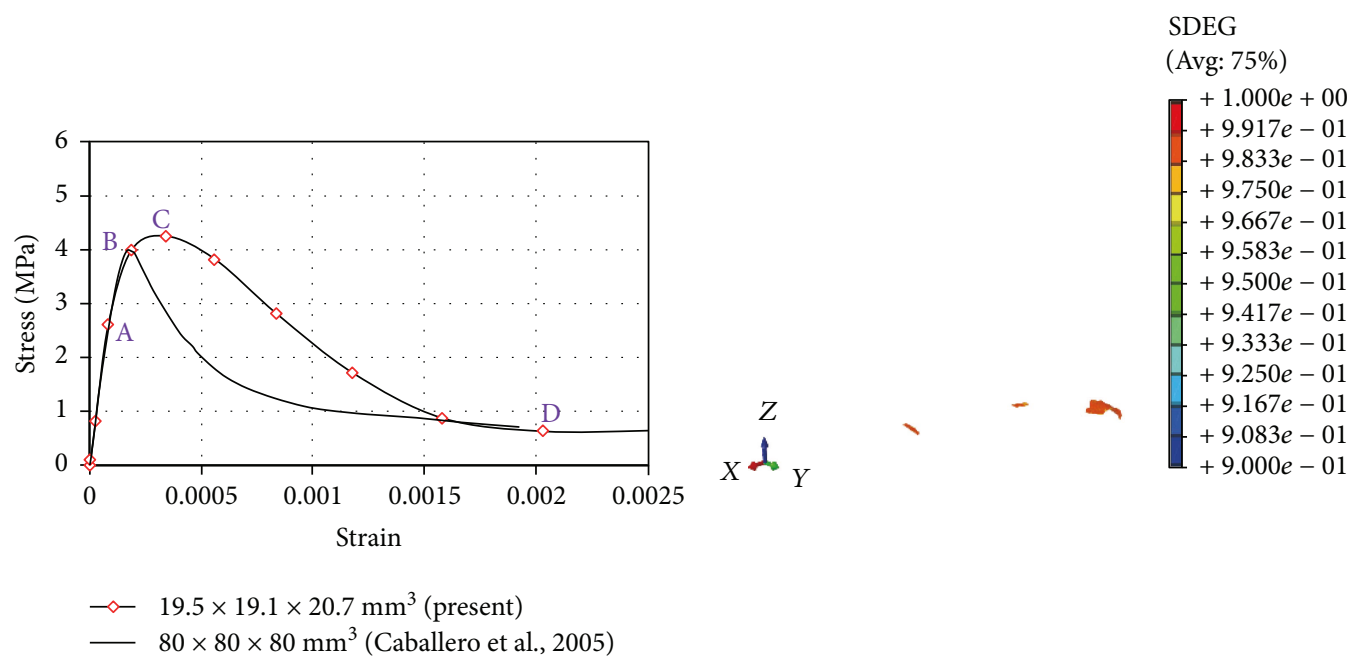

(a) Stress-strain curve

(b) State A $(\varepsilon=0.00008)$

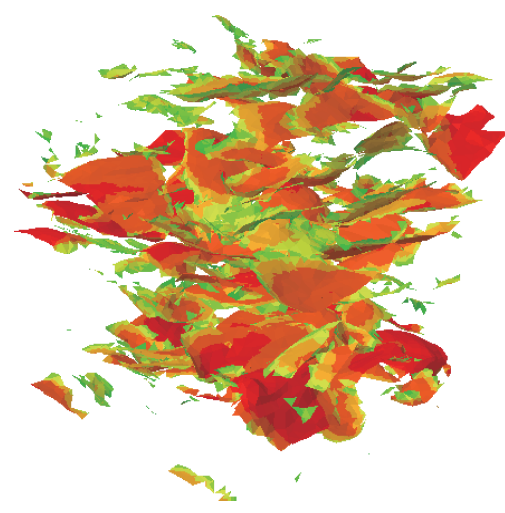

(c) State B $(\varepsilon=0.00019)$

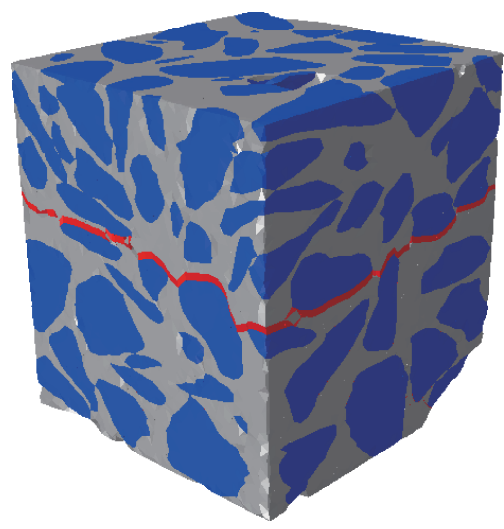

(e) Cracked sample (DSF $=10^{*}$ )

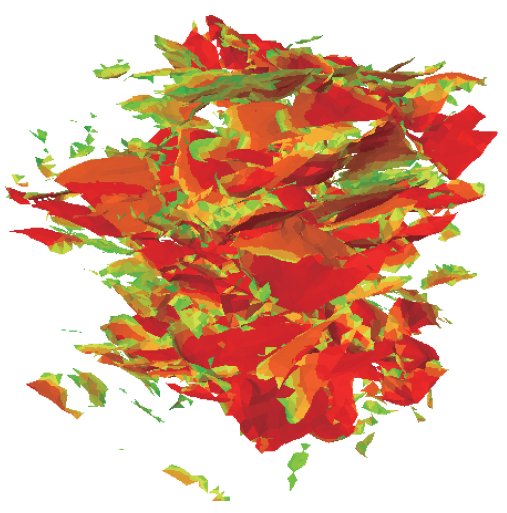

(d) State $\mathrm{C}(\varepsilon=0.00034$, peak $)$

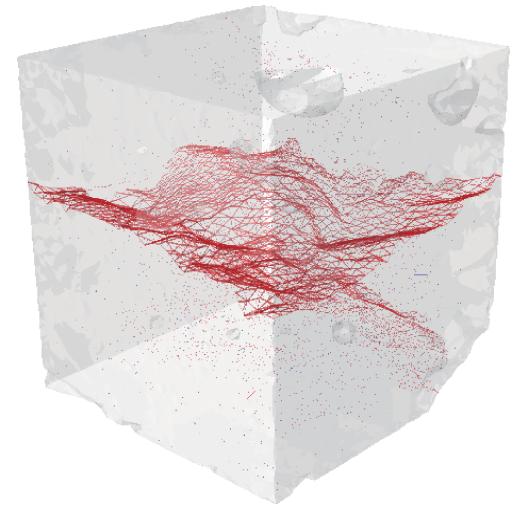

(f) Internal crack surfaces (DSF $=2^{*}$ )

FIGURE 13: Stress-strain curve and damage propagation under tension. ${ }^{*}$ DSF is displacement scale factor.

responses were mainly due to variances of sample size and phase proportions, that is, volume fractions of aggregates are $54.8 \%$ and $20 \%$ for the present sample and those in [21].

The cohesive elements in red represent those with damage index $\mathrm{SDEG}=1$, namely, cracks. At the load point $\mathrm{A}$, there were only a few damaged CIEs. However, many microcracks initiated quickly before the peak load (point C), at which many cracks have already propagated. The final crack pattern is shown in Figures 13(e) and 13(f). It can be seen that, unlike the complicated crack distribution in Figures 13(c) and 13(d), the 3D crack path was finally formed by connecting the cracks at aggregate-cement interfaces and those in the cement. Meanwhile, other cracks were closed due to the stress redistribution. The specimen was split into two pieces through the centre. The internal 3D cracking process is very complicated, demonstrating that the $3 \mathrm{D}$ FE simulation is a very powerful tool to unveil the damage and failure mechanisms. 


\section{Conclusions}

This paper presents an application of micro XCT to microstructure characterisation of concrete and its cracking process using in situ compression tests. The damage evolution was characterised using both $2 \mathrm{D}$ tomography slices and the 3D CT images with distribution of the voids and cracks throughout the compression. The localised 3D fracture evolution process was realistically presented through the 3D crack surfaces at different load steps. The spatial distribution of voids and cracks illustrates the complex heterogeneity and uncertainty in the specimen. After the $3 \mathrm{D}$ segmentation of the image model, the size distributions of the aggregates and pores could provide useful information for generating virtual concrete structures and particle shape analysis of aggregates.

The uniaxial compression test was reproduced numerically by transforming the segmented image model into a $3 \mathrm{D}$ FE mesh with inserted cohesive interface elements. A good agreement between the force-displacement curves from the FE simulation and the XCT test was obtained. This study demonstrates that combining the in situ micro XCT tests and image-based FE modelling is a very promising and effective technique to investigate the internal damage and fracture behaviour in multiphasic composites such as concrete.

\section{Data Availability}

The XCT scanned image data used to support the findings of this study are available from the corresponding author upon request.

\section{Conflicts of Interest}

The authors declare that there is no conflict of interests regarding the publication of this paper.

\section{Acknowledgments}

The authors would like to acknowledge the assistance provided by the Manchester X-ray Imaging Facility, which was funded in part by the EPSRC (Grant nos. EP/F007906/1, $\mathrm{EP} / \mathrm{F} 001452 / 1$, and $\mathrm{EP} / \mathrm{I} 02249 \mathrm{X} / 1)$. The research is funded by the UK EPSRC (Grant nos. EP/J019763/1 and EP/ J019992/1) and supported by the Natural Science Basic Research Plan in Shaanxi Province (2017JQ5052), China Postdoctoral Science Foundation (2017M610654), and Fundamental Research Funds for the Central Universities in China (nos. Z109021614 and 2452017112).

\section{References}

[1] W. Ren, Z. Yang, R. Sharma, C. Zhang, and P. J. Withers, "Two-dimensional X-ray CT image based meso-scale fracture modelling of concrete," Engineering Fracture Mechanics, vol. 133, pp. 24-39, 2015.

[2] T. Ponikiewski, J. Katzer, M. Bugdol, and M. Rudzki, "X-ray computed tomography harnessed to determine 3D spacing of steel fibres in self compacting concrete (SCC) slabs," Construction and Building Materials, vol. 74, pp. 102-108, 2015.
[3] A. S. Agar-Ozbek, J. Weerheijm, E. Schlangen, and K. van Breugel, "Investigating porous concrete with improved strength: testing at different scales," Construction and Building Materials, vol. 41, pp. 480-490, 2013.

[4] E. Masad, S. Saadeh, T. al-Rousan, E. Garboczi, and D. Little, "Computations of particle surface characteristics using optical and X-ray CT images," Computational Materials Science, vol. 34, no. 4, pp. 406-424, 2005.

[5] S. T. Erdogan, P. N. Quiroga, D. W. Fowler et al., "Threedimensional shape analysis of coarse aggregates: new techniques for and preliminary results on several different coarse aggregates and reference rocks," Cement and Concrete Research, vol. 36, no. 9, pp. 1619-1627, 2006.

[6] A. Almhdie, O. Rozenbaum, E. Lespessailles, and R. Jennane, "Image processing for the non-destructive characterization of porous media. Application to limestones and trabecular bones," Mathematics and Computers in Simulation, vol. 99, pp. 82-94, 2014.

[7] S. A. McDonald, G. Dedreuil-Monet, Y. T. Yao, A. Alderson, and P. J. Withers, "In situ 3D X-ray microtomography study comparing auxetic and non-auxetic polymeric foams under tension," Physica Status Solidi (B), vol. 248, no. 1, pp. 4551, 2011.

[8] J. Marrow, C. Reinhard, Y. Vertyagina, L. Saucedo-Mora, D. Collins, and M. Mostafavi, "3D studies of damage by combined X-ray tomography and digital volume correlation," Procedia Materials Science, vol. 3, pp. 1554-1559, 2014.

[9] T. T. Nguyen, J. Yvonnet, M. Bornert, and C. Chateau, "Initiation and propagation of complex 3D networks of cracks in heterogeneous quasi-brittle materials: direct comparison between in situ testing-micro CT experiments and phase field simulations," Journal of the Mechanics and Physics of Solids, vol. 95, pp. 320-350, 2016.

[10] X. Lu, S. D. Rawson, and P. J. Withers, "Effect of hydration and crack orientation on crack-tip strain, crack opening displacement and crack-tip shielding in elephant dentin," Dental Materials, vol. 34, no. 7, pp. 1041-1053, 2018.

[11] D. Ngo and A. C. Scordelis, "Finite element analysis of reinforced concrete beams," ACI Journal Proceedings, vol. 64, no. 3, pp. 152-163, 1967.

[12] N. Michailidis, F. Stergioudi, H. Omar, and D. N. Tsipas, "An image-based reconstruction of the 3D geometry of an Al open-cell foam and FEM modeling of the material response," Mechanics of Materials, vol. 42, no. 2, pp. 142$147,2010$.

[13] Y. Huang, Z. Yang, W. Ren, G. Liu, and C. Zhang, "3D mesoscale fracture modelling and validation of concrete based on in-situ X-ray computed tomography images using damage plasticity model," International Journal of Solids and Structures, vol. 67-68, pp. 340-352, 2015.

[14] X. Su, Z. Yang, and G. Liu, "Finite element modelling of complex 3D static and dynamic crack propagation by embedding cohesive elements in Abaqus," Acta Mechanica Solida Sinica, vol. 23, no. 3, pp. 271-282, 2010.

[15] X. F. Wang, Z. J. Yang, J. R. Yates, A. P. Jivkov, and C. Zhang, "Monte Carlo simulations of mesoscale fracture modelling of concrete with random aggregates and pores," Construction and Building Materials, vol. 75, pp. 35-45, 2015.

[16] P. Yan, J. Zhang, Q. Fang, Y. Zhang, and J. Fan, "3D numerical modelling of solid particles with randomness in shape considering convexity and concavity," Powder Technology, vol. 301, pp. 131-140, 2016. 
[17] Z. J. Yang, X. T. Su, J. F. Chen, and G. H. Liu, "Monte Carlo simulation of complex cohesive fracture in random heterogeneous quasi-brittle materials," International Journal of Solids and Structures, vol. 46, no. 17, pp. 3222-3234, 2009.

[18] X. Yang, Z. You, Z. Wang, and Q. Dai, "Review on heterogeneous model reconstruction of stone-based composites in numerical simulation," Construction and Building Materials, vol. 117, pp. 229-243, 2016.

[19] Z. Yang, W. Ren, R. Sharma et al., "In-situ X-ray computed tomography characterisation of $3 \mathrm{D}$ fracture evolution and image-based numerical homogenisation of concrete," Cement and Concrete Composites, vol. 75, pp. 74-83, 2017.

[20] A. Hillerborg, M. Modéer, and P. E. Petersson, "Analysis of crack formation and crack growth in concrete by means of fracture mechanics and finite elements," Cement and Concrete Research, vol. 6, no. 6, pp. 773-781, 1976.

[21] C. M. López, I. Carol, and A. Aguado, "Meso-structural study of concrete fracture using interface elements. II: compression, biaxial and Brazilian test," Materials and Structures, vol. 41, no. 3, pp. 601-620, 2008.

[22] S. A. McDonald, F. Motazedian, A. C. F. Cocks, and P. J. Withers, "Shear cracking in an $\mathrm{Al}$ powder compact studied by X-ray microtomography," Materials Science and Engineering: $A$, vol. 508, no. 1-2, pp. 64-70, 2009.

[23] M. Mostafavi, S. A. McDonald, P. M. Mummery, and T. J. Marrow, "Observation and quantification of threedimensional crack propagation in poly-granular graphite," Engineering Fracture Mechanics, vol. 110, pp. 410-420, 2013.

[24] AVIZO, AVIZO User's Guide, FEI Visualization Sciences Group, 2013.

[25] S. C. Yuan and J. P. Harrison, "Development of a hydromechanical local degradation approach and its application to modelling fluid flow during progressive fracturing of heterogeneous rocks," International Journal of Rock Mechanics and Mining Sciences, vol. 42, no. 7-8, pp. 961-984, 2005.

[26] S. Erdem, A. R. Dawson, and N. H. Thom, "Influence of the micro- and nanoscale local mechanical properties of the interfacial transition zone on impact behavior of concrete made with different aggregates," Cement and Concrete Research, vol. 42, no. 2, pp. 447-458, 2012.

[27] H.-K. Man and J. M. van Mier, "Size effect on strength and fracture energy for numerical concrete with realistic aggregate shapes," International Journal of Fracture, vol. 154, no. 1-2, pp. 61-72, 2008.

[28] M. H. A. Beygi, M. T. Kazemi, I. M. Nikbin, J. Vaseghi Amiri, S. Rabbanifar, and E. Rahmani, "The influence of coarse aggregate size and volume on the fracture behavior and brittleness of self-compacting concrete," Cement and Concrete Research, vol. 66, pp. 75-90, 2014.

[29] Z. Qian, E. J. Garboczi, G. Ye, and E. Schlangen, "Anm: a geometrical model for the composite structure of mortar and concrete using real-shape particles," Materials and Structures, vol. 49, no. 1-2, pp. 149-158, 2016.

[30] A. Yin, X. Yang, and Z. Yang, "2D and 3D fracture modeling of asphalt mixture with randomly distributed aggregates and embedded cohesive cracks," Procedia IUTAM, vol. 6, pp. 114-122, 2013.

[31] Simpleware, Scan IP, + FE and + CAD Version 4.3 Reference Guide, Simpleware Ltd, 2011.

[32] ABAQUS, ABAQUS 6.10 Online Documentation, Internet Manual, 2010.
[33] X. T. Su, Z. J. Yang, and G. H. Liu, "Monte Carlo simulation of complex cohesive fracture in random heterogeneous quasibrittle materials: a 3D study," International Journal of Solids and Structures, vol. 47, no. 17, pp. 2336-2345, 2010.

[34] W. Ren, Z. Yang, and R. Sharma, "3D meso-scale image-based fracture modelling of concrete using cohesive elements," in Proceedings of the 22nd UK Conference of the Association for Computational Mechanics in Engineering, pp. 140-143, Exeter, UK, April 2014.

[35] S. A. McDonald and P. J. Withers, "Combining X-ray microtomography and three-dimensional digital volume correlation to track microstructure evolution during sintering of copper powder," The Journal of Strain Analysis for Engineering Design, vol. 49, no. 4, pp. 257-269, 2014.

[36] M. Mostafavi, Y. Vertyagina, C. Reinhard et al., "3D studies of indentation by combined X-ray tomography and digital volume correlation," Key Engineering Materials, vol. 592-593, pp. 14-21, 2014.

[37] DaVis, “User's manual," Gottingen: LaVision Gmb H, 2012. 


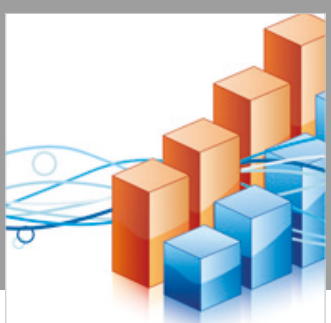

Advances in

Operations Research

\section{-n-m}
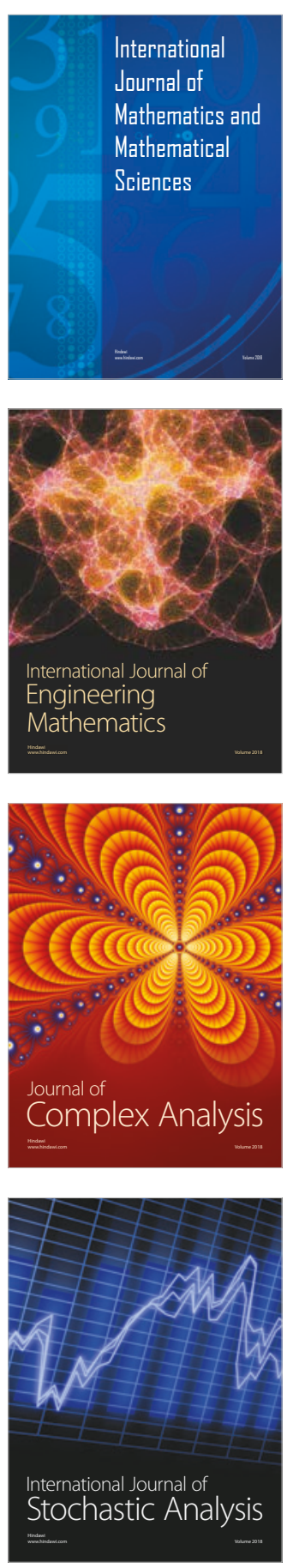
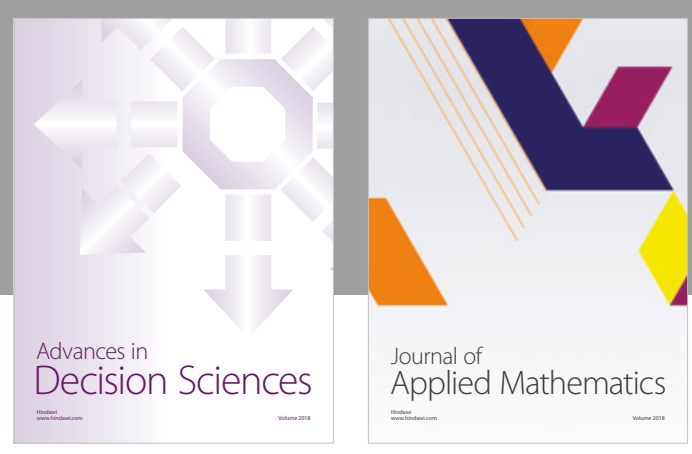

Journal of

Applied Mathematics
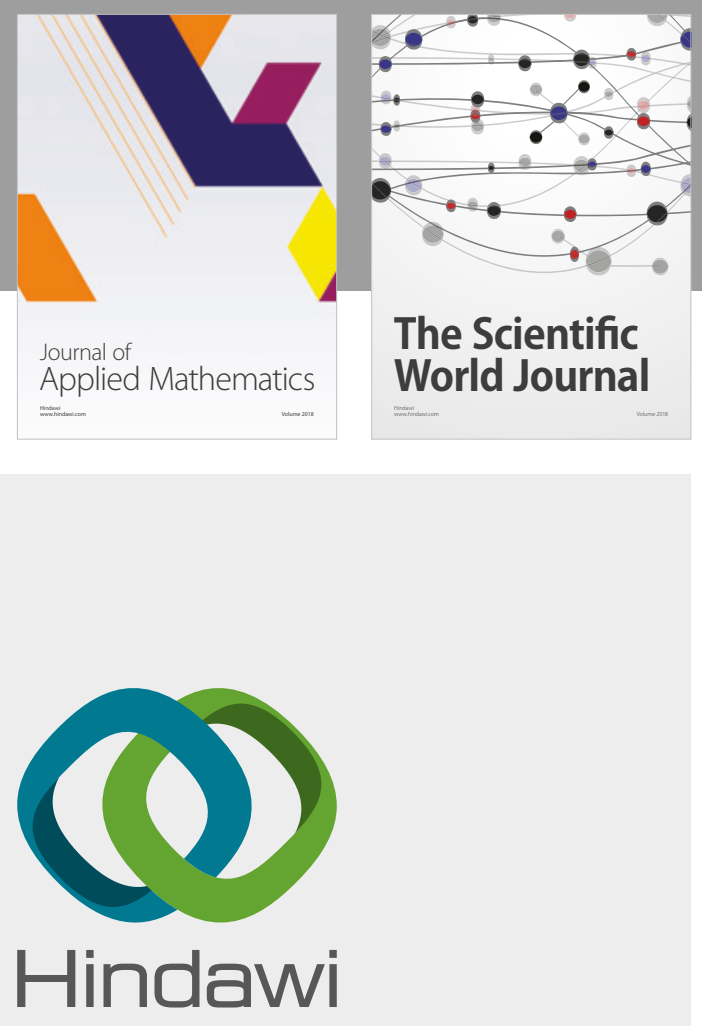

Submit your manuscripts at

www.hindawi.com

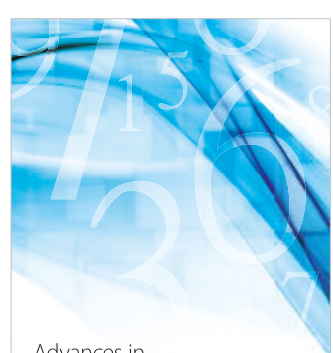

Advances in
Numerical Analysis
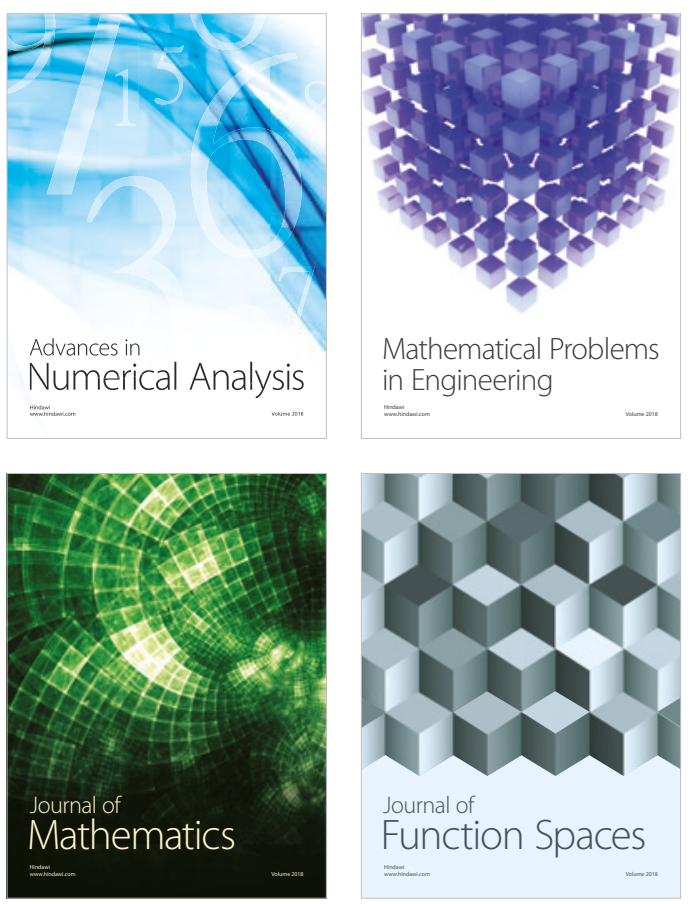

Mathematical Problems in Engineering

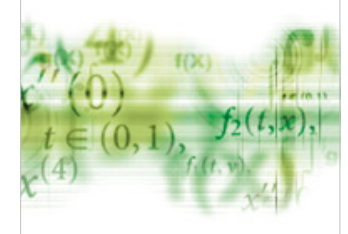

International Journal of

Differential Equations

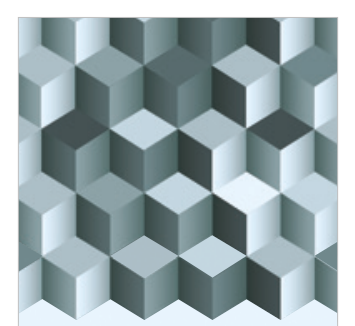

Journal of

Function Spaces
The Scientific

World Journal

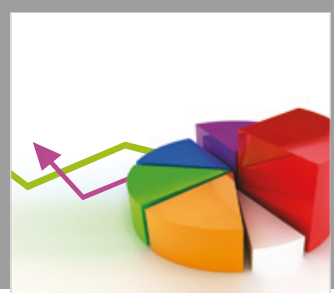

Journal of

Probability and Statistics
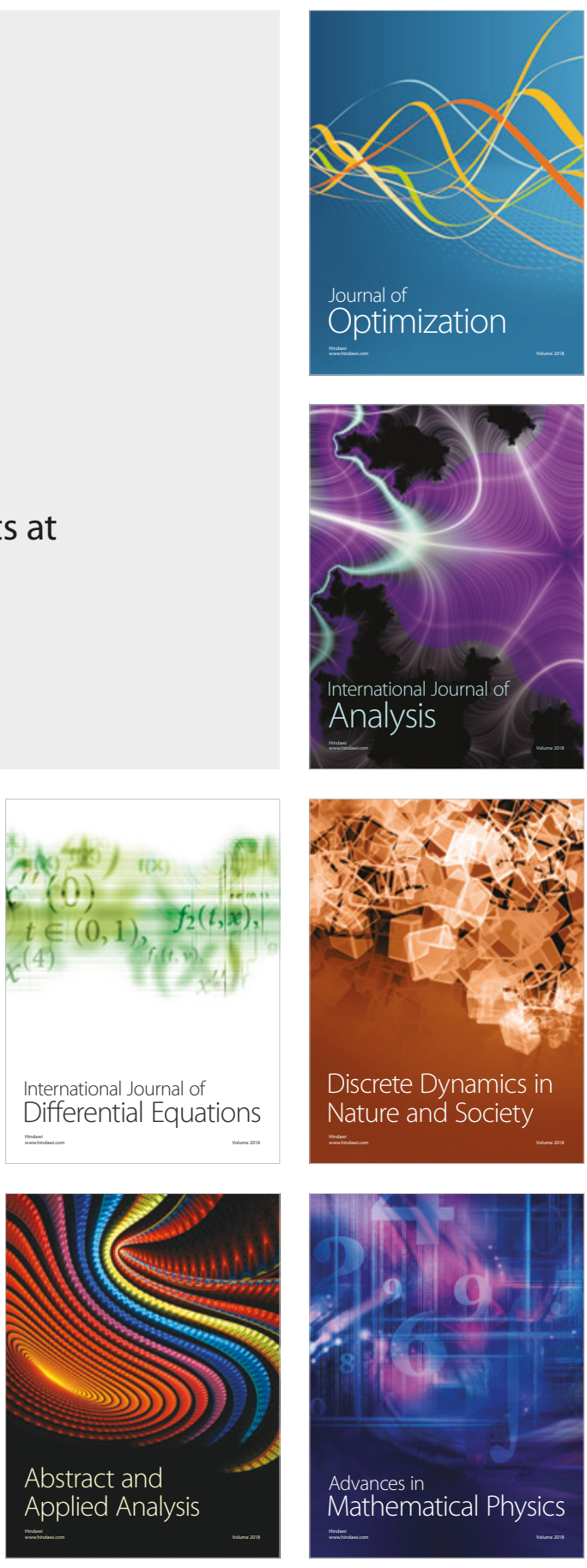